\title{
Rights and Protection of Persons with Disabilities in Bangladesh: A Critical Review
}

\author{
Md Asraful Islam ${ }^{1 *} \&$ Shajadi Fatema Juhara ${ }^{2}$ \\ ${ }^{1}$ PhD Fellow, Ahmad Ibrahim Kulliyah of Laws (AIKOL), International Islamic University Malaysia (IIUM). \\ ${ }^{2}$ Advocate, Dhaka Judge Court
}

\begin{abstract}
This paper examines the legal and regulatory framework governing rights and protection of persons with disabilities (PWDs) of Bangladesh in a critical manner. The purpose of this study is to explore and analyze the existing legal system concerning disability rights in Bangladesh with a view to identifying the loopholes and suggesting recommendations for possible solutions. The study uses a legal and doctrinal research methodology followed by an analytical approach. In identifying and interpreting data both primary and secondary legal sources are considered. The study reveals that the current legal framework regulating disability rights in Bangladesh is not well structured and in reality, persons with disabilities are not properly protected by law. Hence, a comprehensive legislation with effective implementation mechanism is indispensable for Bangladesh to enforce the rights of PWDs diligently and efficiently.
\end{abstract}

Keywords- Persons with disabilities, Disability rights, Legal framework, Protection, Bangladesh

\section{INTRODUCTION}

$\mathrm{T}$ The concept of disability rights is of recent origin and comparatively a new domain in international human rights law. In the modern context of human rights, it is one of the most demanding issues almost in all states. Bangladesh is not also far behind this issue despite of the absence of an effective legal mechanism on disability rights, although a set of substantive and procedural laws are relevant to ensuring such rights. The continuing efforts and movements for recognition, promotion and protection of rights of persons with disabilities in Bangladesh has a decade old history but a snail's pace development. However, it is true for many countries that existence of law and implementation of the same always do not go parallel and Bangladesh is not an exception to that. This paper is an attempt to examine the prevailing legal and social framework covering rights of persons with disabilities in Bangladesh and also to find the present status of disability rights and to identify the areas for further development keeping consistency with international standard and better practices. It also attempts to find out the loopholes of disability laws of Bangladesh and to suggest some reforms to different stakeholders so that necessary actions might be taken for the betterment of the persons with disabilities and their human rights can be assured equally.

\section{CONCEPTUAL ANALYSIS}

Disability is a physical or mental impairment of a human being that limits his/her normal functioning of life. Disability involves dysfunction of one or more levels of physical function, individual activity or social participation. It could occur at birth or during the course of life. Disability can be categorized into different types, such as hearing disability, visual disability, physical disability, speech disability, mental disability etc. A person may be affected with a single type of disability or multiple disabilities at the same time (BBS, 2015). In accordance with the purposes and principles of the Charter of the United Nations and the International Bill of Human Rights, persons suffering from any form of disability are not only entitled to exercise all the civil, political, economic, social and cultural rights embodied in these and other instruments, but also they are recognized as being entitled to exercise them on an equal basis (UN, 2020).

Rights of persons with disabilities are one of the most misunderstood areas of the development arena in Bangladesh, and also one of the most common forgotten development agenda. In Bangladesh, issues concerning persons with disabilities are not addressed by mainstream human rights, women's rights, child rights, religious minorities' rights or indigenous peoples' rights organizations. However, People with disabilities in Bangladesh are equally entitled to all the rights, entitlements and fundamental freedoms enshrined in the Constitution. In addition to the constitution, all other international treaties and instruments concerning human rights that the Government becomes a party to, either by signature or ratification, should be accessible to people with disabilities on an equal basis with others. One of the major reasons for people with disabilities in Bangladesh not enjoying their rights and entitlements properly is the general inaccessibility of infrastructure.

The prevalence of disability in Bangladesh is believed to be high for reasons relating to overpopulation, extreme poverty, illiteracy, lack of awareness, and above all, lack of medical care and services. People with disabilities face difficulties to take part in education, employment, social activities, and indeed all aspects of life. Disable persons can have equal participation in social, cultural, employment sectors with the appropriate State facilities. While most of the developed countries across the world have already established rights and opportunities for disable people to have equal access to socioeconomic and national activities like normal people have, the government of Bangladesh has also seriously addressed the disability righteous perspectives issues and enacted disability 
laws under the Protection of the Rights of the Persons with Disabilities Act, 2013. But due to poor performance in implementation of the law and people's attitude towards disable persons are still big concerns in protecting the rights of disable persons in Bangladesh. Currently, they are amongst the most vulnerable group of people in the society irrespective of their race, sex, gender, financial status or whatsoever. This vulnerable situation of persons with disabilities need to be changed significantly to ensure their better lifestyle. For this, substantial reforms are necessary in the current laws and practices. Unfortunately, a few of such attempts were taken in recent past.

\section{DISABILITY AND STATISTICAL DILEMMA}

In Bangladesh, no comprehensive empirical study has been conducted till today to determine the prevalence of disabilities. The few studies that have been conducted reflect a medical rather than a social model of disabilities, and those are also limited in geographical coverage. Those studies generally suggest a disability prevalence rate between 5 to 12 per cent. This is close to the WHO estimate, which states that about $10 \%$ of the total population (approximately 16 million) of Bangladesh are disabled, of which half a million are multihandicapped including three million children (Khandaker Jahurul Alam, 2009). The total figure of disability is increasing with population growth and ageing. Disability on this scale represents not only a major health issue but also a prime cause of poverty and underdevelopment.

The available data and information of Bangladesh Bureau of Statistics, based on health and medical perspective shows that proportional prevalence of disability of different categories at all ages are visual 20\%, physical (including leprosy and goiter) $39 \%$, mental $13 \%$, speech $13 \%$, hearing $9 \%$ and autism $6 \%$ (BBS, 2015).

Fig 1: Disability Rate in Bangladesh (BBS, 2015)

Disability Rate (Bangladesh)

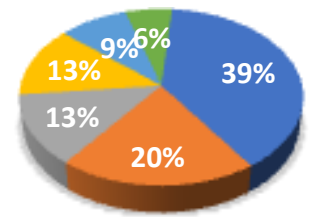

Physical

- Visual

Mental

$\square$ Speech

Hearing

Autism

Disability related statistics has been in a terrible state in Bangladesh. There is irregularity among findings of several studies. The Government of Bangladesh (GOB) surveys in 1982, 1986 and 1998 estimated a national prevalence rate of disability at $0.64 \%, 0.5 \%$ and $1.60 \%$ respectively. Action AidBangladesh and Social Assistance and Rehabilitation for the Physically Vulnerable (SARPV) found the disabled population at $8.8 \%$ of the total population and Bangladesh Protibandi Kalayan Samiti records 7.8\% (BBS, 2015).

In May 2019, the UN Committee on the Rights of Persons with Disabilities requested Bangladesh to indicate measures envisaged to collect better data on persons with disabilities. In response, the Government of Bangladesh explained how the number of people with disabilities are now detailed on the Government's Disability Information System (DIS) website. According to DIS (2020), 1,810,821 people in Bangladesh have a disability of which $1,108,859$ are men, 699,473 are women, and 2,489 are described as third gender. However, other estimates of the prevalence rate of disability in Bangladesh indicate that there is much room for confusion. The national census of 2011 of Bangladesh reported disability prevalence to be 1.4 percent (1.3 percent female, 1.5 percent male). The Household Income and Expenditure Survey (HIS), 2010 conducted by the Bangladesh Bureau of Statistics (BBS) found the disability prevalence rate to be 9.07 percent. Based on World Health Survey Data (2002-2004), the Global Disability Report found disability prevalence in Bangladesh to be 31.9 percent. According to the alternative CRPD report of 2019, around 24 million people, out of 160 million, have disabilities in Bangladesh. All these statistics suggest that existing data on disability is not adequate, reliable or comprehensive. The Bangladesh Bureau of Statistics (BBS) and the Bangladesh Institute of Development Studies have yet to conduct any comprehensive mapping of persons with disabilities in Bangladesh (Stephen James Thompson, 2020). Hence, it is a time demand to conduct a reliable survey in Bangladesh to determine the exact prevalence of disabilities so that proper measures can be taken for protection of their rights and privileges.

\section{IV.SOCIAL BARRIERS OF PERSONS WITH DISABILITIES}

In Bangladesh, many families are unable to take proper care of members with disabilities due to economic reasons. Sometimes superstition and fear of persons with disabilities also result in their isolation. According to Bangladesh Protibondhi Kayallan Somoti (BPKS) Report, 2004 (BPKS, 2004), the major difficulties faced by persons with disabilities (PWDs) include the following:

- Deficiency in access to medical services: In Bangladesh, medical facilities are inadequate and there are very few specialists to address PWDs.

- Poor Access to education: In education sector, there is lack facilities and teachers and tuition is very costly. Disabled students face discriminations and are often ridiculed by other students, and many parents do not want their children to study alongside disabled students,

- Limited access to employment: In both the public and private sector employments are generally not available for PWDs because potential employers lack confidence regarding PWDs' ability to fulfil work duties. 
- Access to transportation: In Bangladesh, access to public transportations for persons with disabilities is nearly impossible though there is specific legal provision for reserving seats in public transports. Despite three accessible buses were introduced in the capital city by a private transportation company in 2003, the overall transportation system in the country is totally inaccessible to PWDs.

- Children with disabilities (CWDs): CWDs are susceptible to diseases and sicknesses such as tetanus and acute respiratory infections, and malnutrition. They tend to suffer from discrimination in their own families in terms of food and clothing provided, and abuse by others. They are among the most vulnerable groups in the country;

- Women with disabilities (WWDs): WWDs are deemed to be victims of double disability because of their status as women and due to their disability. The needs of WWDs are generally ignored and social service facilities for these women are practically non-existent.

\section{NATIONAL LEGAL FRAMEWORK ON DISABILITY RIGHTS}

The Convention on the Rights of Persons with Disabilities (CRPD) is the basic international document regarding protection of the rights of the disabled persons. On December 13, 2006, the UN General Assembly unanimously adopted the CRPD, which later entered into force on May 3, 2008. Bangladesh was the $91^{\text {st }}$ UN Member State to sign the CRPD in May 2007, and the 8th UN Member State to ratify it in November 2007. In doing so, it became imperative on the country to align all its laws and policies in line with the CRPD. In May 2008, Bangladesh became the 16th UN Member State to accede (ratify without signing) to the Optional Protocol of the CRPD. By following these steps, Bangladesh expressed its commitment and allegiance to the international community regarding the rights of persons with disabilities (Md Nayem Alimul Hyder, 2016). Accordingly, the Protection of the Rights of the Persons with Disabilities Act, 2013 was passed with a view to ensuring the rights and dignity of persons with disabilities.

The Constitution of the People's Republic of Bangladesh states that 'no citizen shall, on grounds only of religion, race, caste, sex or place of birth be subjected to any disability, liability, restriction or condition with regard to access to any place of public entertainment or resort, or admission to any educational institution'(Bangladesh Constitution, 1972). In Bangladesh, the first National Policy for the Disabled was approved by the Government in 1995. An Action Plan to execute this Policy was approved in 1996. In 2001 a comprehensive disability legislation entitled 'The Bangladesh Persons with Disability Welfare Act (2001)' was adopted by the Parliament. The Act lists 10 specific priority areas: (1) Disability prevention, (2) Identification, (3) Curative treatment, (4) Education, (5) Health care, (6) Rehabilitation and employment, (7) Transport and communication, (8)
Culture, (9) Social security, and (10) Self-help organizations (World Bank, 2004).

In early December 2003, a Regional Symposium on Disability was held in Dhaka hosted by the National Forum of Organizations Working with the Disabled (NFOWD) with participation from 24 Ministries and Government departments. The outcome of this Symposium is the Dhaka Declaration on Disability, 2003 which states about 20 items in a plan of action for implementation.

Following its own national provisions and international commitment, Bangladesh incorporated the provisions of the CRPD by legislating the Rights and Protection of Persons with Disabilities Act 2013. This Act repeals the prior Disability Welfare Act 2001 in Bangladesh. Subsequently, the Government of Bangladesh formulated the Rights and Protection of Persons with Disabilities Rules in 2015 for further clarification of the 2013 Act (Brac, 2018). This initiative demonstrates the promptness of the Government of Bangladesh in dealing with this issue.

Table 1: Bangladesh policy and development on disability

\begin{tabular}{|c|c|}
\hline 1993 & $\begin{array}{c}\text { National coordination committee on disability was } \\
\text { established under the Ministry of Social Welfare }\end{array}$ \\
\hline 1995 & National policy on disability was adopted \\
\hline 1996 & $\begin{array}{c}\text { Action plan on disability approved outlining the plan for the } \\
\text { implementation of the national policy }\end{array}$ \\
\hline 2000 & $\begin{array}{c}\text { National Foundation for the Development of Disabled } \\
\text { Persons was established }\end{array}$ \\
\hline 2001 & Disability Welfare Act was passed by the Parliament \\
\hline 2006 & $\begin{array}{c}\text { National Plan of Action-II was approved by the national } \\
\text { coordination committee }\end{array}$ \\
\hline 2007 & $\begin{array}{c}\text { Government of Bangladesh ratified the United Nations } \\
\text { Convention on Persons with Disabilities (UNCRPD) }\end{array}$ \\
\hline 2009 & $\begin{array}{c}\text { A Disability Rights Watch Group and National Forum of Law } \\
\text { and Legislation committee were formed }\end{array}$ \\
\hline 2013 & $\begin{array}{c}\text { Rights and Protections of Persons with Disabilities 2013 was } \\
\text { enacted }\end{array}$ \\
\hline 2015 & $\begin{array}{c}\text { Rights and Protection of Persons with Disabilities Rules 2015 } \\
\text { were formulated }\end{array}$ \\
\hline
\end{tabular}

The policy makers of the government must adhere to the legislation enacted by the parliament and comply with international human rights instruments ratified by the government including its optional protocol for persons with disabilities. Allocations of Business of the different ministries of the government should be inclusive of concerns of persons with disabilities. Currently all development issues concerning disability is placed under the Ministry of Social Welfare. As a result other ministries concerned with development work such as, Ministry of Primary \& Mass Education, Ministry of Education, Ministry of Women \& Children Affairs, Ministry of Youth \& Sports, Ministry of Communication, Ministry of ICT, Ministry of Information etc. do not take into account disability as a cross-cutting development issue in their respective ministry's annual development programs. A large number of public servants are not oriented and trained on disability and development. Consequently, a lack of 
awareness, indifferent attitude and negative mindset seriously act as obstacles for the development of persons with disabilities in Bangladesh (MA Choudhuri, 2009).

\section{RIGHTS AND PROTECTION OF PERSONS WITH DISABILITIES IN BANGLADESH}

In Bangladesh, rights and protections of persons with disabilities are ensured and affected mainly by the Rights and Protection of Persons with Disabilities Act 2013. According to this Act, PWDs are entitled to following rights and protections:

- Rights to survive and develop to full extent;

- Equal legal recognition and access to justice in all cases like ordinary people;

- Inheritance right;

- Freedom of expression and access to information;

- Right to live in society with parents, valid or legal guardian, children and family, right to establish a marital relationship, and form a family;

- Accessibility right;

- Right to participate fully and effectively in social, economic and state activities considering the type of disability;

- Right to participate in integrated education considering the availability of opportunity at all levels;

- Right to employment at government and non-government organizations;

- Right to continue employment if disability occurs in the course of employment, or to receive appropriate rehabilitation and compensation;

- Right to get protection from oppression and right to avail a safe and healthy environment;

- The right to have the highest quality of health care on the basis of availability;

- Right to get an environment and reasonable accommodation conducive to the necessary comfort in academic institutions and workplaces in all applicable cases;

- Right to get support services and rehabilitation with the aim of becoming fully integrated in all spheres of social life by acquiring physical, mental and technical capacities;

- Persons with disabilities who are dependent on the parent or family if unfortunately get separated from the parent or family, have the rights to proper accommodation and rehabilitation;

- Right to participate in cultural, entertainment, tourism, leisure and sports activities;

- Right to adopt Bangla as gesture language by hearing and speech impaired persons in accordance with their willingness;

- The right to privacy of personal information
- Right to formation and management of self-help organizations and welfare organizations or associations;

- Right to receive national identity card, inclusion in the voter list, voting and participation in the election;

- Any other rights as determined by the government in the official gazette.

These rights are enforced by several committees. According to this Act, five types of committees are established based on their responsibilities and process of work from national to town levels. The National Coordinating Committee is a 28member Committee formed by the Ministry of Social Welfare, different ministry representatives and representatives from Disabled People's Organizations (DPOs) and it works for the enforcement of the rights of persons with disabilities at national level. The National Executive Committee consists of 17 members formed by the Ministry of Social Welfare to execute the decisions of the National Coordination Committee. The District Committee is a 17 -member Committee formed by the Deputy Commissioner to enforce the rights of persons with disabilities and to execute the decisions of the Government and National Coordination Committee at the District level. The Upzilla Committee is composed of 14 members by the Upzilla Nirbahi Officer to serve at Upzilla level. City Committee is formed with nine members in the city area under the city corporation (RPPDA, 2013).

The Rights and Protection of Persons with Disabilities Act, 2013 focuses more on bureaucracy than serving the actual purpose. It promotes the formation of different committees to ensure the rights of persons with disabilities. However, it does not mention the mechanism by which community can engage with those committees. There is no provision of representation from persons with disabilities or inclusion of disability experts in these committees. Offenses against PWDs are a must punishable issue and need prompt action. It would be the best option to create a separate forum with a different set of judges to deal with matters under the proposed Act. There are no special provisions made for women with disabilities too (Munzur Murshid and Mainul Haque, 2020).

\section{DISABILITY AND POVERTY: THE VICIOUS CIRCLE}

According to the World Health Organization, approximately 10 percent of the world's population has a disability. In developing countries, this population numbers at least $400,000,000$, and they are among the poorest of the poor. The UN cites a prevalence rate of world disability of about $10 \%$. Within established economies, estimates vary from $8 \%$ to over 20\% (HCDG, 2021).

Disability and poverty cause and reinforce each other. Poor nutrition, dangerous working and living conditions, limited access to health care, poor hygiene, bad sanitation, inadequate information about the causes of impairment, war and conflict 
and natural disasters create disabilities of which as many as $50 \%$ are preventable. Disability, particularly of the head of the household, exacerbates poverty of the whole family due to social exclusion (World Bank, 2004). It has been estimated that $15-20 \%$ of the poor in developing countries are disabled, which is significantly higher than the commonly assumed $10 \%$ people with disabilities in general population.

Experts from the United Kingdom Disabled Persons Council attribute the connection between disability and poverty to many systemic factors that promote a "vicious circle" (R. Yeo and K. Moore, 2003). Statistics affirm the mutually reinforcing nature of special needs and low socioeconomic status, showing that people with disabilities are significantly more likely to become impoverished and people who are impoverished are significantly more likely to become disabled. Barriers presented for those with disabilities can lead individuals to be deprived of access to essential resources, such as opportunities for education and employment, thus causing them to fall into poverty. Likewise, poverty places individuals at a much greater risk of acquiring a disability due to the general lack of health care, nutrition, sanitation, and safe working conditions that the poor are subject to (Yeo and Moore, 2003).

In 1997 IMPACT Foundation Bangladesh carried out a small study on the relationship between poverty and disability in Chuadanga district. Poverty was measured in terms of landholdings (acres) and the results show that $61 \%$ of people with disabilities lived in households of less than $1 / 2$ acre. $20 \%$ of people with disabilities lived in households of $1 / 2-2.99$ acres and $19 \%$ in households with more than 3 acres of land (World Bank, 2004).

\section{CONCLUSION}

Disability is a curse that can never be vanquished. Disability will always remain in our society, with the entire social stigma attached to it. But in the backdrop of all these problems, the silver lining is that the government is showing an increasing interest in the Disability sector, and at the same time, displaying a keen interest to work hand in hand with the nongovernment sector. But to make some real progress in this field in a developing country like Bangladesh, an all-out effort from all quarters is required. Now that the revised Allocation of Business of different Ministries and Departments is in its final stages of approval, it can be anticipated that, when this change sees the light of day, all the development ministries of the government, in addition to the Ministry of Social welfare, will have some concrete role to play. Similarly, at the nongovernment sector, many NGOs are also increasingly taking up disability works. The Corporate sector is also opening up to the issue, creating new avenues for employment and other types of support. Thus, it is recommended that the government of Bangladesh should enact a comprehensive legislation with easy implementation mechanism for enforcing the rights of persons with disabilities diligently and efficiently so that each and every sector of the government and other stakeholders can work together for the development of PWDs. We hope that in near future we would be able to establish a strong legal framework for enforcing the rights and ensuring legal protection for the persons with disabilities (PWDs).

\section{REFERENCES}

[1] Bangladesh Protibondhi Kallyan Somity (BPKS). 13-17 February 2004.

[2] BBS.(2015). Disability in Bangladesh: Prevalence and Pattern, Bangladesh Bureau of Statistics. Population Monograph: Volume 5.

[3] Brac. (2018). Study on the Rights and Protection of the Persons with Disabilities Act 2013: Adaptation, Application and Recommendation.

[4] MA Choudhuri. (2009). National legislative measures on disability and its harmonization with Convention on the Rights of Persons with Disabilities (CRPD) in Bangladesh, UNESCAP.

[5] World Bank. (2004). Disability in Bangladesh: A Situation Analysis, Final Report, May 2004, The Danish Bilharziasis Laboratory for the World Bank, People's Republic of Bangladesh.

[6] HCDG. (2021). Disability and Poverty, Hill County Disabled Group. Retrieved from <http://hcdg.org/poverty.htm> accessed 16 January 2021.

[7] Khandaker Jahurul Alam. (2009). Bangladesh and Persons with Disabilities, Asia Pacific Human Rights Center, FOCUS, Volume 55. Retrieved from<https://www.hurights.or.jp/archives/focus/section2/ 2009/03/bangladesh-and-persons-with-disabilities.html> accessed 16 January 2021.

[8] Md Nayem Alimul Hyder. (2015). 'Protecting the rights of disabled persons in Bangladesh', The Financial Express, 07 March, 2015.

[9] Munzur Murshid \& Mainul Haque. (2020). Disability Brief in Single Chapter and Bangladesh Perspectives: A Rapid Overview. Advances in Human Biology, Volume 10, Issue 2.

[10] State of the Rights of Persons with Disabilities in Bangladesh. Disability Rights Watch Group (DRWG) Bangladesh. (2009).

[11] Stephen James Thompson.(2020). Disability Inclusive Development Situational Analysis Bangladesh, Institute of Development Studies, Bangladesh Situational Analysis, Version II.

[12] The Constitution of the People's Republic of Bangladesh. (1972). Article 28(3)

[13] The Disability Welfare Act. (2001).

[14] The Rights and Protections of Persons with Disabilities Act (RPPDA). (2013). Sections 16, 17,18,19,20,21, 22,23, and 24.

[15] United Nations (UN). (2020). "Human Rights and Disabled Persons-International Human Rights Standards", United Nations Enable. Retrieved from <https://www.un.org/esa/socdev/enable/dispaperdes1.htm.> Accessed 4 August 2020.

[16] R. Yeo \& K. Moore. (2003). Including disabled people in poverty reduction work: "Nothing about us, without us". World Development 31, 571-590. 